\title{
Exercício Físico na Dependência Química
}

\section{INTRODUÇÃO}

O Uso de substâncias psicoativas na região Central de São Paulo, conhecida como Cracolândia, tem aumentado a fragilidade física e social do indivíduo dependente químico. Como intervenção das Políticas Públicas, o Programa Recomeço Helvetia oferta vários cuidados a esses indivíduos, frente às suas demandas, sendo que um desses cuidado é a prática do Exercício Físico. O Exercício Físico bem estruturado e embasado cientificamente, atua como um elo terapêutico importante, intervindo na autoestima e sensação de prazer na dependência química. Os Exercícios Físicos são utilizados para provocar mudanças no cotidiano e melhorar a qualidade de vida, reduzindo estresse, melhorando o bem estar emocional e físico que, por vezes, estão negligenciados. O Exercício Físico é uma estratégia de hábitos saudáveis e prazerosos que podem substituir o "bem estar" causado pelo uso das drogas.

\section{OBJETIVO}

Descrever a prática do Exercício Físico como elo terapêutico contribuindo na aderência dos dependentes químicos ao serviço.

\section{MÉTODO}

Trata-se de um relato de experiência que descreve a aderência dos usuários de substâncias psicoativas aos Exercícios Físicos ofertados pelo Centro de Convivência Helvetia. Os Exercícios Físicos compreendem: exercícios de força, modalidades esportivas, alongamento e resistência, sendo que todos são planejados e estruturados de forma singular. São ofertados, diariamente 100 vagas de 45 minutos/dia, de segunda a sexta-feira. Além das outras atividades externas fixas, compreendendo futebol, passeios de bicicleta, caminhadas, participação em campeonatos externos, visitas a culturais.

\section{RESULTADOS}

O Exercício Físico é uma intervenção terapêutica no processo de reestabelecimento fisiológico, cognitivo, social, melhorando a aderência ao tratamento e diminuindo a vulnerabilidade social. De janeiro a novembro de 2018, foram realizados 15.334 atendimentos na academia e que aumentarem para a construção de vínculos, proporcionaram saídas das cenas de uso, auxiliaram na prevenção de doenças, no resgate da autonomia e melhoraram a autoestima dos usuários. O Exercício Físico age em diversos sistemas do corpo, seja nas adaptações físicas ou contribuindo na educação e no resgate da cidadania.

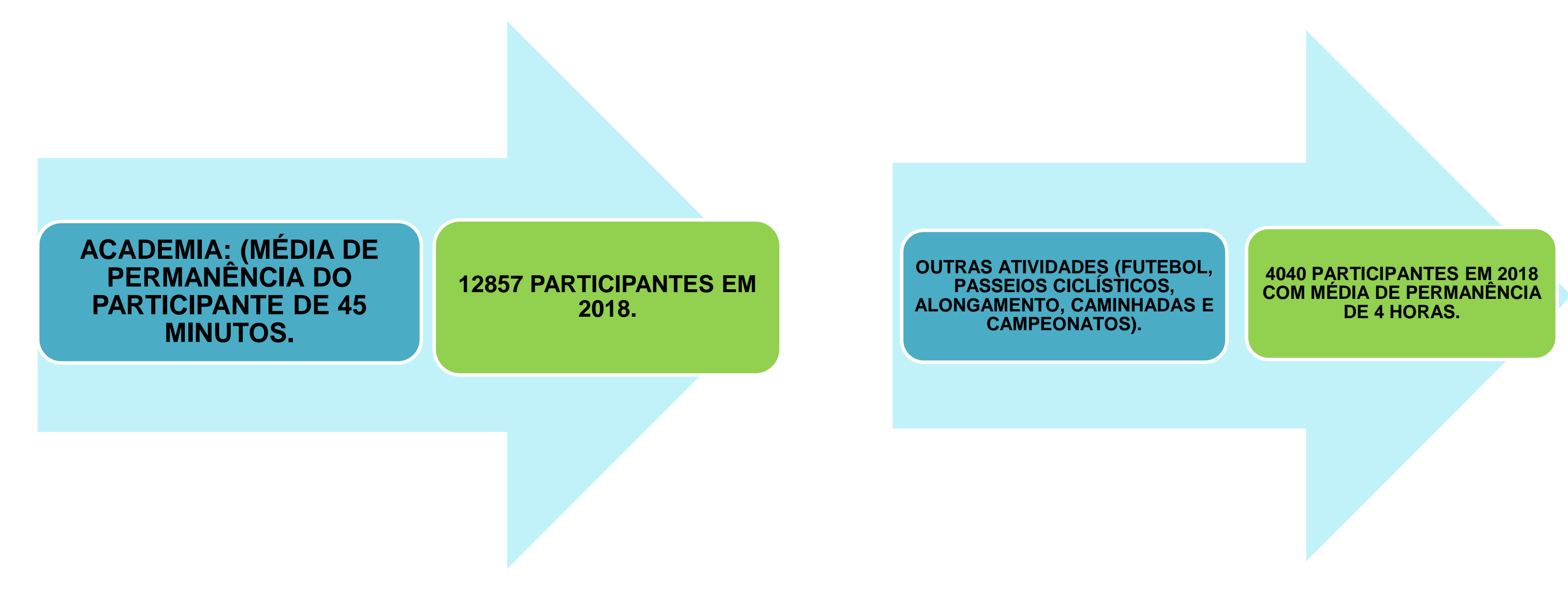

\section{CONCLUSÃO}

Praticar Exercícios Físicos e a sua compreensão, ativa as sensações de prazer e incitam a manter a prática. Ao incorporar em sua rotina a o programa de exercícios físicos, o dependente químico aprenderá novas ferramentas para liberar estresse, adquirir autoconfiança e resgatar os elos afetivos e sociais fragilizados.
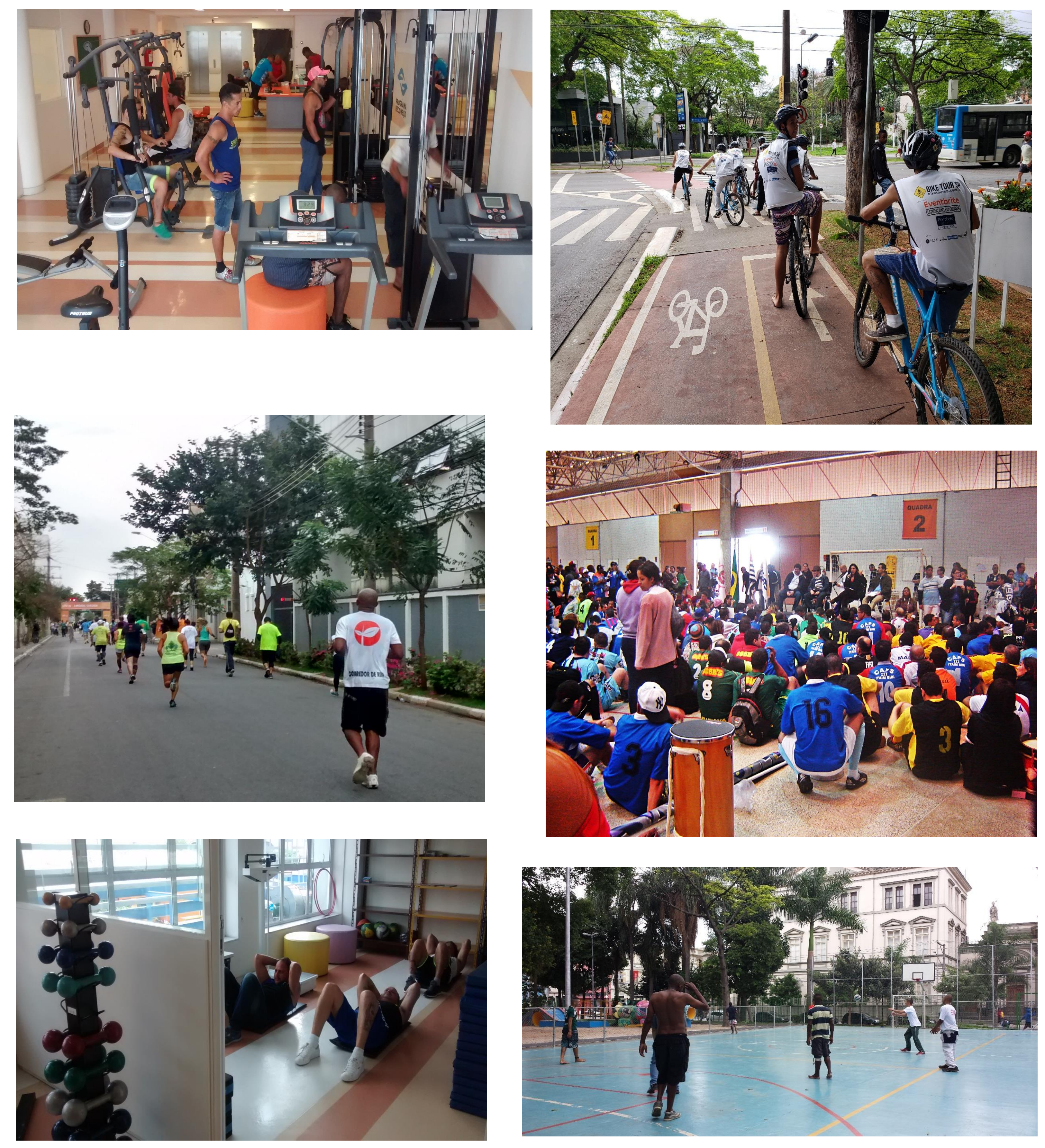

\section{REFERÊNCIAS}

-DE TILIO, R .et.al. Medos e Expectativas de Usuários de Drogas em Situação de Rua. Revista Sociedade de Psicoterapias Analíticas Grupais do Estado de São Paulo, n. 16 vol. 2, pag. $75-87,2015$

-Ribeiro, M. e Laranjeira, R. (2012). O Tratamento do usuário de crack. Artmed. Porto Alegre,664p.

-PACHECO, R.S., SOARES, M.C.L.B. A Atuação do Profissional de Educação Física em equipes multidisciplinares da saúde pública e privada. Ensaios \& Diálogos, Rio Claro,v. 9, n.1, p.139-158, jul-dez 2016. 